\title{
Stress Analysis of Double-row Corrugated Steel Pipes
}

\author{
Chi Zhang ${ }^{1, a^{*}}$, Shui Wan ${ }^{1, b}$ \\ ${ }^{1}$ School of Transportation, Southeast University, Nanjing, Jiangsu, 210096, China \\ azhangchipi@126.com, 'rlanyu421@163.com
}

\begin{abstract}
Keywords: Corrugated steel pipe, Spacing, Hoop stress, Displacement
Abstract. The corrugated steel pipes utilize the advantages of steel, such as high ductility, tensile, compressive and shear strength. So the problem of foundation deformation and uneven settlement of foundation can be solved nicely. The corrugated steel pipes show good adaptability for adverse geological condition. In the article, the stress under different filling depth and varying row spacing is calculated and compared with single-row corrugated steel pipes. And then the influence of row spacing on stress of double-row corrugated steel pipes is analyzed. It is concluded that row spacing has little influence on the maximum stress when the spacing is more than 0.25 times of diameter, while the construction quality and convenience should be taken into account preferentially.
\end{abstract}

\section{Introduction}

As early as 1784 corrugated pipes appeared in Britain for the first time. Then American leaded the study of feasibility of corrugated pipes used as culverts and channels in 1800.The corrugated pipes soon applied to culvert firstly. In 1931, Australia built the first highway tunnel with steel corrugated pipes. Japan revised the "Code for highway" in 1990, which included the design standards for corrugated pipes. The application of steel corrugated pipes in our country can be traced back to 1950s in the Qinghai-Tibet highway project during which more than one hundred corrugated pipes culvert were built in order to deal with settlement and deformation of foundation caused by permafrost and other adverse geological conditions. For its nice performance, the corrugated pipe culverts have been applied widely in highway corrugated pipe culvert projects. Up to now, the maximum diameter of corrugated pipe culvert for closed section is 12 meters, while the maximum span for open cross section is 7.4 meters. Filling height ranges from 0.5 meters to highest 60 meters.

After two hundred years of development, steel corrugated pipes has been widely used in drainage culverts with high fill, replacing small span bridge, interchange, bridge strengthening, pipeline crossing and so on. Currently, the domestic and foreign research and application mainly concentrate on single-row corrugated steel pipes while the studies on double-row corrugated steel pipes are lacking. So it is necessary to figure out the stress properties of double-row corrugated steel pipes under different filling depth and varying row spacing. And then compare it with the stress of the single-row steel corrugated pipes, so that the similarities and differences between them are clear.

\section{Finite element analysis of steel corrugated pipe culverts}

Selection of Measurement Points. For the longitudinal length of steel corrugated pipes is longer than other dimensions, it can be regarded as a plane strain problem. Thus the finite element model includes two waves only to save the computing time. In the cross section, the results are got from half of the corrugated pipes according to the symmetry. The measuring points of corrugated pipes are as follows: the top, the bottom, the middle and 45 degree. For double-row corrugated steel pipes, one of the corrugated steel pipes are chosen to extract the stress results. The numbers of measuring points are 1, 2, 3, 4, 5, B, C, D. Fig.1 depicts the measuring points of double-row corrugated steel pipes and single-row corrugated steel pipes clearly. 


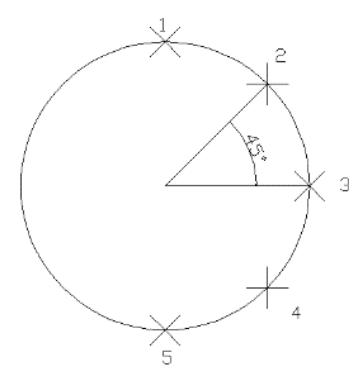

a) Single
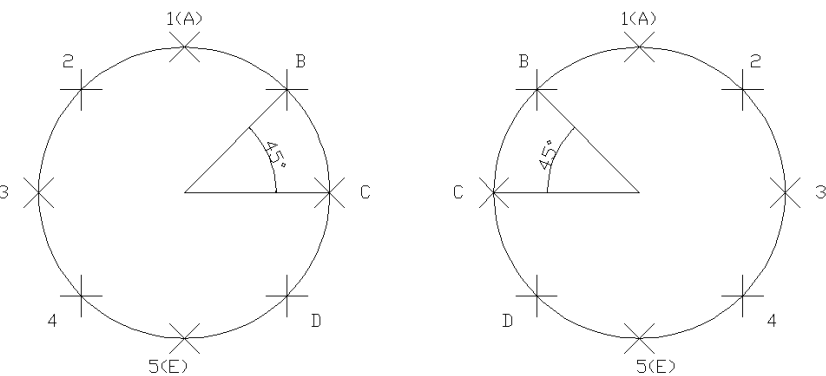

b) Double

Fig.1 Schematic diagram of the measuring points

Finite Element Model. As for the simulation in Ansys, the solid45 is used for soil mass and the shell63 is used for steel corrugated pipes. For the sake of computational efficiency, the mesh of soil far away from corrugated pipes is sparse. On the contrary the soil mass elements is more delicate when it is near the corrugated pipes.Fig. 2 show the integral mesh and the steel corrugated pipes mesh in detail.

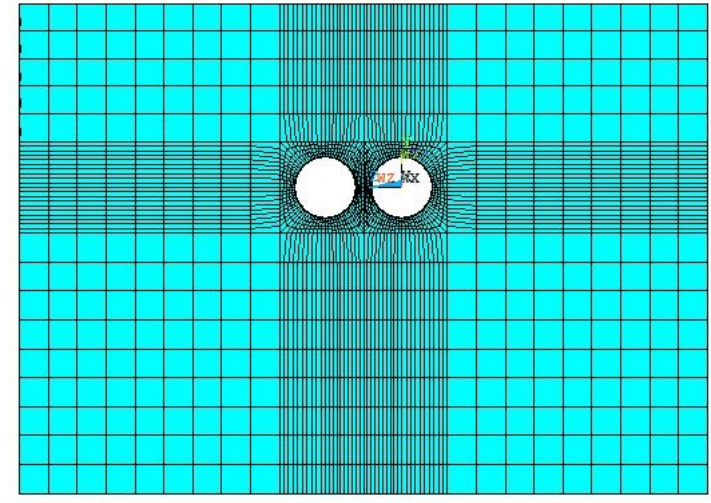

a) Integral Mesh

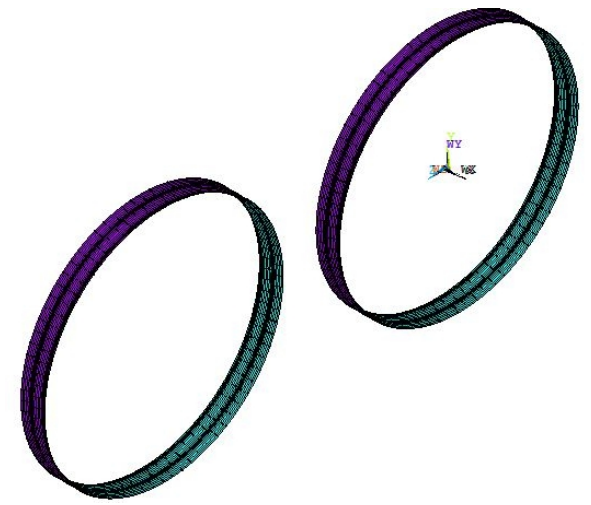

b) Mesh in Detail of Pipes

Fig.2 Mesh of Finite Element Model

Boundary Conditions. The double-row and single-row corrugated steel pipes have the same boundary conditions as shown in Fig.3. The boundary conditions are as follows:(1)Bottom surface, all degrees of freedom are constrained.(2) Side faces: horizontal freedom are constrained.(3) Top surface, keep free.(4) Longitudinal of corrugated steel pipes, keep free.

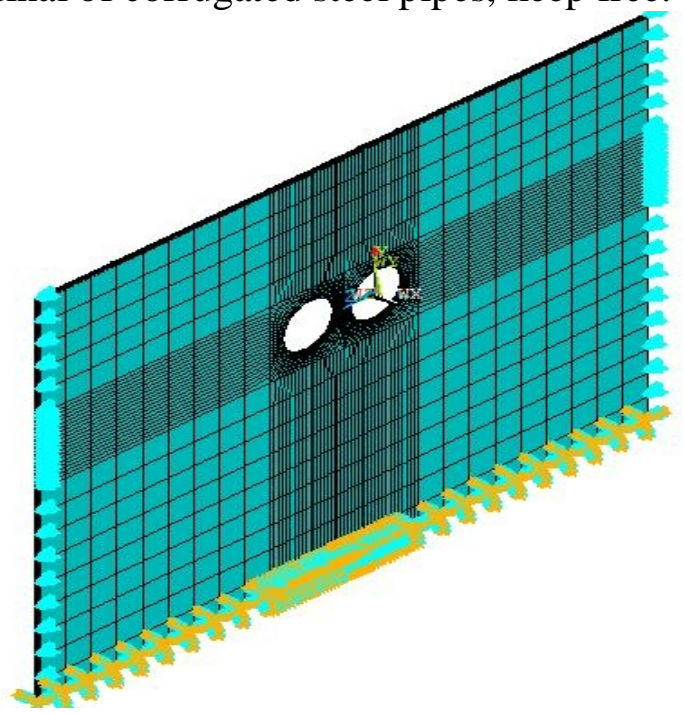

Fig. 3 boundary conditions

Calculating Parameters. Parameters of corrugated pipes: wave length $200 \mathrm{~mm}$, wave height $55 \mathrm{~mm}$, thickness $3 \mathrm{~mm}$, density $7800 \mathrm{~kg} / \mathrm{m}^{3}$, elasticity modulus $2.1 \times 10^{11} \mathrm{~Pa}$, Poisson's ratio 0.3 .

Parameters of soil: density $1900 \mathrm{~kg} / \mathrm{m}^{3}$, elasticity modulus $3.8 \times 10^{7} \mathrm{~Pa}$, Poisson's ratio 0.23 . 
Stress Characteristics of Corrugated Pipes. According to classical shell theory, compared with circumferential stress and axial stress, the compressive stress is negligible. After calculating, it is indicated that the maximum stress usually appear at point of 1, 3, 5, A, C or E, either wave crest or wave trough. In the article, when comparing the variation of maximum stress, only the circumferential stress is took into consideration. The maximum stress refer to the circumferential stress outside the steel corrugated pipes and positive stress means compressive, while negative stress means the measuring point is in tension.

\section{Result analysis}

Stress Analysis. The diameter of steel corrugated pipes is 2 meters under 10 meter soil. Stress and deformation of double-row steel corrugated pipes is calculated with different spacing. The value of spacing is $5 \mathrm{~d}, 4 \mathrm{~d}, 3 \mathrm{~d}, 2 \mathrm{~d}, \mathrm{~d}, 0.5 \mathrm{~d}, 0.25 \mathrm{~d}$ ( $\mathrm{d}$ stands for the diameter of pipes) for each calculation. The Fig.4 shows the stress nephogram of single-row steel corrugated pipes which illustrates that the maximum tensile stress appears at point 5 and maximum compressive stress appears at point 3 .

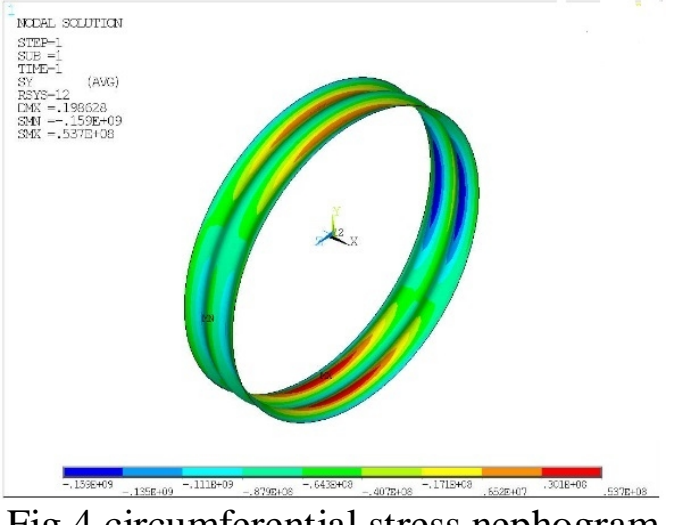

Fig.4 circumferential stress nephogram

Variation of circumferential stress is shown in Fig.5.a).In observing Fig.5.a), it can be note that stress of measuring points varies differently with the change of the distance between two corrugated pipes. For the points 1, 2, 3, 4, 5, the stress has a slight increase, while there is an obvious decline $t$ at point $\mathrm{B}$ and $\mathrm{D}$. The maximum variation appears at point $\mathrm{C}$. When the spacing is less than two times diameter, the stress at point $\mathrm{C}$ begins to increase rapidly and become the maximal stress as the spacing is less than $0.25 \mathrm{~d}$ at wave crest. But it varies a little when the spacing approaches from $5 \mathrm{~d}$ to $2 \mathrm{~d}$.

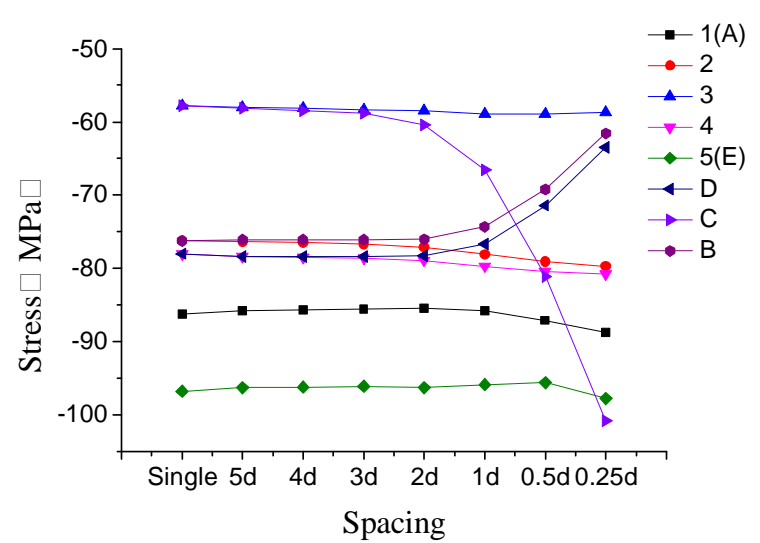

a) wave crest

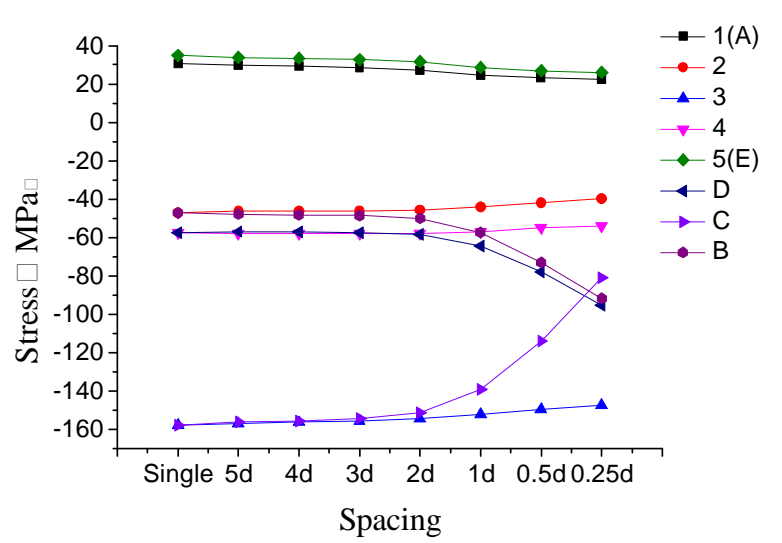

b) wave trough

Fig.5 variation of circumferential stress along with spacing

The Fig.5.b) depicts the variation of circumferential stress at wave trough. As shown in the Fig.5.b), the variation of stress differs from the point at wave crest. All points have a slight decline of its stress except B and D. The increasing tendency for stress at B and D become significant when the spacing is less than $2 \mathrm{~d}$.But the maximum stress still appears at point 3 at wave trough. The 
maximum stress is not increase until the spacing is less than $0.25 \mathrm{~d}$ taking the wave crest points and wave trough points into consideration.

Table 1 and table 2 illustrate the percent change of stress of double-row corrugated steel pipes together with single-row corrugated steel pipes under the circumstance of different spacing. Positive numbers means that the stress increases while the negative number means that the stress decrease.

Table 1 percent change of stress (wave crest)

\begin{tabular}{ccccccccccc}
\hline Percent & Point & Point & Point & Point & Point & Point & \multirow{2}{*}{ Point B } & Point & Point D & Point \\
Change & 1 & 2 & 3 & 4 & 5 & A & & E \\
$5 \mathrm{~d}$ & $-0.46 \%$ & $0.17 \%$ & $0.35 \%$ & $0.51 \%$ & $-0.52 \%$ & $-0.46 \%$ & $-0.22 \%$ & $0.52 \%$ & $0.51 \%$ & $-0.52 \%$ \\
$4 \mathrm{~d}$ & $-0.58 \%$ & $0.30 \%$ & $0.52 \%$ & $0.64 \%$ & $-0.62 \%$ & $-0.58 \%$ & $-0.22 \%$ & $1.21 \%$ & $0.51 \%$ & $-0.62 \%$ \\
$3 \mathrm{~d}$ & $-0.70 \%$ & $0.56 \%$ & $0.87 \%$ & $0.77 \%$ & $-0.72 \%$ & $-0.70 \%$ & $-0.22 \%$ & $1.73 \%$ & $0.51 \%$ & $-0.72 \%$ \\
$2 \mathrm{~d}$ & $-0.81 \%$ & $1.09 \%$ & $1.21 \%$ & $1.15 \%$ & $-0.52 \%$ & $-0.81 \%$ & $-0.35 \%$ & $4.50 \%$ & $0.38 \%$ & $-0.52 \%$ \\
$1 \mathrm{~d}$ & $-0.46 \%$ & $2.40 \%$ & $1.90 \%$ & $2.18 \%$ & $-0.93 \%$ & $-0.46 \%$ & $-2.58 \%$ & $15.22 \%$ & $-1.67 \%$ & $-0.93 \%$ \\
$0.5 \mathrm{~d}$ & $1.04 \%$ & $3.71 \%$ & $1.90 \%$ & $3.08 \%$ & $-1.24 \%$ & $1.04 \%$ & $-9.27 \%$ & $40.31 \%$ & $-8.46 \%$ & $-1.24 \%$ \\
$0.25 \mathrm{~d}$ & $2.90 \%$ & $4.50 \%$ & $1.56 \%$ & $3.59 \%$ & $1.03 \%$ & $2.90 \%$ & $-19.23 \%$ & $74.39 \%$ & $-18.59 \%$ & $1.03 \%$ \\
\hline
\end{tabular}

Table 2 percent change of stress (wave trough)

\begin{tabular}{ccccccccccc}
\hline Percent & Point 1 & Point 2 & Point & Point & \multirow{2}{*}{ Point 5 } & Point & Point & Point & Point & Point \\
Change & & & 4 & & B & C & D & E \\
5d & $-3.45 \%$ & $-1.49 \%$ & $-0.70 \%$ & $0.52 \%$ & $-2.87 \%$ & $-3.45 \%$ & $1.49 \%$ & $-1.01 \%$ & $-0.87 \%$ & $-2.87 \%$ \\
4d & $-4.75 \%$ & $-1.70 \%$ & $-1.01 \%$ & $0.70 \%$ & $-4.30 \%$ & $-4.75 \%$ & $2.34 \%$ & $-1.52 \%$ & $-0.52 \%$ & $-4.30 \%$ \\
3d & $-7.02 \%$ & $-2.12 \%$ & $-1.39 \%$ & $0.70 \%$ & $-6.02 \%$ & $-7.02 \%$ & $3.18 \%$ & $-2.34 \%$ & $-0.17 \%$ & $-6.02 \%$ \\
2d & $-10.92 \%$ & $16.14 \%$ & $-2.09 \%$ & $0.52 \%$ & $-9.46 \%$ & $-10.92 \%$ & $6.37 \%$ & $-4.18 \%$ & $1.57 \%$ & $-9.46 \%$ \\
$1 \mathrm{~d}$ & $-19.70 \%$ & $-6.16 \%$ & $-3.67 \%$ & $-0.87 \%$ & $-17.77 \%$ & $-19.70 \%$ & $22.08 \%$ & $-11.75 \%$ & $12.00 \%$ & $-17.77 \%$ \\
$0.5 \mathrm{~d}$ & $-24.25 \%$ & $-10.83 \%$ & $-5.25 \%$ & $-4.35 \%$ & $-22.64 \%$ & $-24.25 \%$ & $54.99 \%$ & $-27.85 \%$ & $35.83 \%$ & $-22.64 \%$ \\
$0.25 \mathrm{~d}$ & $-26.85 \%$ & $-15.29 \%$ & $-6.71 \%$ & $-6.26 \%$ & $-25.50 \%$ & $-26.85 \%$ & $94.90 \%$ & $-48.73 \%$ & $65.91 \%$ & $-25.50 \%$ \\
\hline
\end{tabular}

Displacement Analysis. In observing of table 3 and table 4, it can be noted that vertical displacement decline with the spacing getting closer. More accurately, when the spacing is bigger than $\mathrm{d}$, the change is slight. But the displacement decreases quickly after the spacing is smaller than d. Horizontal displacement increases slightly and becomes stable after the spacing is less than $0.25 \mathrm{~d}$.

Table 3 vertical and horizontal displacement [mm]

\begin{tabular}{ccccccccc}
\hline Displacement & Single & $5 \mathrm{~d}$ & $4 \mathrm{~d}$ & $3 \mathrm{~d}$ & $2 \mathrm{~d}$ & $1 \mathrm{~d}$ & $0.5 \mathrm{~d}$ & $0.25 \mathrm{~d}$ \\
Vertical & 12.7 & 12.5 & 12.4 & 12.3 & 12.2 & 12.2 & 11.5 & 10.7 \\
horizontal & 11.8 & 12.4 & 12.44 & 12.6 & 12.8 & 12.8 & 13.2 & 13.2 \\
\hline
\end{tabular}

Table.4 percent change of vertical and horizontal displacement

\begin{tabular}{ccccccccc}
\hline Percent Change & Single & $5 \mathrm{~d}$ & $4 \mathrm{~d}$ & $3 \mathrm{~d}$ & $2 \mathrm{~d}$ & $1 \mathrm{~d}$ & $0.5 \mathrm{~d}$ & $0.25 \mathrm{~d}$ \\
Vertical & $0.0 \%$ & $-1.6 \%$ & $-2.4 \%$ & $-3.2 \%$ & $-3.9 \%$ & $-3.9 \%$ & $-9.5 \%$ & $-15.8 \%$ \\
horizontal & $0.0 \%$ & $5.1 \%$ & $5.4 \%$ & $6.8 \%$ & $8.5 \%$ & $8.5 \%$ & $11.9 \%$ & $11.9 \%$ \\
\hline
\end{tabular}

\section{Conclusion}

Through the numerical simulation and calculation of the steel corrugated pipe culverts, the following conclusions are drawn:

1. Spacing between the double-row steel corrugated pipes has an influence on the stress compared to the single-row steel corrugated pipes. When the spacing is more than $3 \mathrm{~d}$, the percent change is less than $10 \%$. And the stress varies obviously only when the spacing is less than $2 \mathrm{~d}$. Moreover, despite the increase of stress at some points, the maximum stress changes little, less than 
$5 \%$ at last when the spacing is less than $0.25 \mathrm{~d}$. Therefore, the stress variation along with the spacing changing can be negligible as the maximum stress taken into consideration.

2. Horizontal displacement of double-row corrugated steel pipes increase with the distance narrow down between the two pipes. But the displacement meets the normal demand that the maximal displacement should be less than $5 \%$ of the diameter.

3. The construction quality and convenience should be taken into account preferentially. As compactness and quality of the soil meet the requirement of the specifications, with spacing bigger than $0.25 \mathrm{~d}$, the stress of the double-row steel corrugated pipes is mostly the same as single corrugated pipes.

\section{References}

[1] Haitao.Qian, Experimental study on mechanical characteristics of corrugated pipe culvert, M. Nanjing University of Aeronautics and Astronautics. 2011. (In Chinese)

[2] Yanling Wu, Zhongjv Feng, Yanzhi Wang, Experimental analysis on the stress and deformation characteristics of steel corrugated pipe culvert, J. Journal of Xi'an University of Architecture \& Technology. 2008, 30(4): 1-6. (In Chinese)

[3] Li Feng, Analysis of mechanical properties of corrugated steel pipe culvert with soil-structure interaction, D. Beijing Jiaotong University. 2005. (In Chinese)

[4] Yonggang Wang, Shiliang Dai. Geometric nonlinear analysis of corrugated steel pipes under arbitrary loads J. Journal of Tsinghua University (Philosophy and Social Sciences), 2002, 42(2): 220-223. (In Chinese)

[5] Faxiang.Zhang, Analysis and selection of arch culvert, J. Journal of Hohai University. 1995, 23(3): 58-65. (In Chinese) 